\title{
Assessment of Hamstring: Quadriceps Coactivation without the Use of Maximum Voluntary Isometric Contraction
}

\author{
Gonzalo Torres ${ }^{1}\left(\mathbb{0}\right.$, David Chorro $^{1}$, Archit Navandar ${ }^{2}{ }^{\circ}$, Javier Rueda ${ }^{1}\left({ }^{\circ}\right.$, Luís Fernández $^{3}$ and \\ Enrique Navarro ${ }^{1, *}$ \\ 1 Faculty of Sport Sciences, Biomechanics Laboratory, Universidad Politécnica de Madrid, \\ 28040 Madrid, Spain; gonzalo.torresmar@gmail.com (G.T.); dchorroh@gmail.com (D.C.); \\ javier.rueda7792@gmail.com (J.R.) \\ 2 Faculty of Sport Sciences, Universidad Europea de Madrid, 28670 Madrid, Spain; archit89@gmail.com \\ 3 Medical Services of Atlético de Madrid, Club Atlético de Madrid, 28221 Madrid, Spain; luferro@ceu.es \\ * Correspondence: enrique.navarro@upm.es
}

Received: 3 February 2020; Accepted: 22 February 2020; Published: 29 February 2020

check for updates

Featured Application: Recording quadriceps and hamstrings coactivation by surface electromyography (sEMG) in highly reproducible exercises.

\begin{abstract}
This study aimed to study the coactivation patterns of the hamstring and quadriceps muscle groups during submaximal strength exercises commonly used in injury prevention in soccer without the use of maximum voluntary isometric contraction testing. This was used to compare: (i) the inter-limb differences in muscle activation; (ii) the intra-muscular group activation pattern and (iii) the activation pattern during different phases of the exercise. Muscle activation was recorded by surface electromyography in 19 elite, male, youth soccer players. Participants performed the following: Bulgarian squat, lunge and squat. Electrical activity was recorded for the rectus femoris, vastus medialis, vastus lateralis, biceps femoris and semitendinosus. No significant inter-limb differences were found $\left(F_{1,13}=619 ; p=0.82 ; \eta^{2}=0.045\right)$. Significant differences were found in the muscle activation between individual muscles within the quadriceps and hamstrings muscle group for each of the exercises: Bulgarian squat $\left(\mathrm{F}_{1,18}=331: p<0.001 ; \eta^{2}=0.80\right)$, lunge $\left(\mathrm{F}_{4,72}=114.5 ; p<0.001\right.$; $\left.\eta^{2}=0.86\right)$ and squat $\left(\mathrm{F}_{1,16}=247.31 ; p<0.001 ; \eta^{2}=0.93\right)$. Differences were found between the different phases of each of the exercises $\left(F_{2,26}=52.27 ; p=0.02 ; \eta^{2}=0.80\right)$. The existence of an activation pattern of each of the muscles in the three proposed exercises could be used for muscle assessment and as a tool for reconditioning post-injury.
\end{abstract}

Keywords: electromyography; hamstrings; human performance; prevention; ratio; rehabilitation; soccer

\section{Introduction}

Performance in soccer depends on psychological, physiological and biomechanical factors [1,2]. The study of these factors not only helps improve performance but also works towards injury prevention. Performance and injury prevention are not isolated fields, and the presence of an injury can affect on-field performance. Measurement of the muscular capacity of players is an important factor in the evaluation and prediction of the functional capacity of the player [3].

Muscular capacity has been traditionally measured using isokinetic machines [4,5]. These machines measure the torque generated in isolated joint rotations (for example, in knee flexion and extension), and the torque generated is associated with the primary muscle group responsible for that 
rotation. This could possibly disregard the contribution of individual muscles [4]. Moreover, one must consider that there could be multiple muscle groups responsible for a joint rotation, and that not all muscles of a muscle group participate in specific muscular function. Another drawback of the isokinetic machines is that they produce high muscular fatigue, restricting their regular use during the season [6].

Electromyography (EMG) is a diagnostic tool that could possibly overcome the shortcomings of the isokinetic machines [7-9], and in some cases, even complement the use of isokinetic machines [10]. EMG sensors permit the measurement of muscle activation of individual muscles and determine both the quantification of muscle activation and the timing of the same. In sports, surface EMG sensors are commonly used given their non-invasive nature permitting the measurement of surface muscles. Specifically in soccer, previous studies using EMG have been used to determine asymmetry in soccer players, which can affect both performance [11,12] and injury [13]. Such comparative studies have been carried out in youth soccer players as well $[14,15]$ finding that there may be a neuromuscular pattern and that strength work could be related to a reduction in the injury rate in soccer players.

Asymmetry in soccer players could be offset with proper exercise prescription, which facilitates improvements in musculoskeletal function by addressing the specific needs of the subject as an integral part of any rehabilitative, preventive or maintenance program [16]. Functional weight-bearing exercises have received a significant amount of attention as the preferred mode of exercise for lower extremity strengthening [17]. In studies with EMG, basic movements with additional weight (forward lunge, Bulgarian squat, lateral step-ups, squat) are frequently used so that they are easily replicable [18,19], and such exercises do not cause an excessive muscular fatigue in players, permitting their use throughout the preseason and in-season. These are simple exercises used to strengthen the quadriceps and hamstrings, and their study could provide information about the activation of different muscles of the quadriceps and hamstrings and to differentiate the activation differences in the exercise phases (concentric, isometric and eccentric) [20]. Considering the muscle group that they target, these exercises can be crucial for soccer players given that recent research has shown that monitoring the electrical activity of individual muscles could help in the injury rehabilitation and prevention process [20,21].

Specifically, in the case of soccer players, quadriceps and hamstrings account for $19 \%$ and $16 \%$ of all types of injuries, respectively [22]. The total number of hamstring injuries increased by $4 \%$ on a yearly basis in European soccer from 2001 to 2014, while the total number of injuries increased by $2.3 \%$ [23]. Muscular imbalances have been cited as an important risk factor for hamstring strain injury [24,25]. This has traditionally been evaluated through isokinetic machines [26,27], although recent studies have begun using surface electromyography (sEMG) in different strength exercises. sEMG has been used to evaluate the Nordic hamstring curl [28], the leg curl [29], bilateral open chain [30] and unilateral closed chain exercises like forward lunge, Bulgarian squat and unilateral bridge [31]. Research has shown that these exercises targeting the quadriceps and hamstrings have proved beneficial not only for the rehabilitation of these specific muscle groups but also for the rehabilitation and prevention of anterior cruciate ligament injury, [32] patellofemoral pain syndrome [33] or groin injuries [34].

Studies using sEMG have required the normalization of sEMG signal [35]. Many normalization techniques are available with the maximal voluntary isometric contraction (MVIC) the most commonly used method [35]. However, some controversy exists about its reliability [36,37], leading researchers to study the agonistic-antagonist coactivation of muscles as an alternative by normalizing the electrical activity of one muscle in relation to the other [20]. This can be useful because it gives information on how muscles work synergistically and permits a normalization that is not demanding for the athlete, facilitating its use at any time of the season.

Such a synergistic muscle coactivation is observed in the hamstring and quadriceps in different movements in soccer such as sprinting, kicking, jumping and also in strengthening exercises used in soccer training. Submaximal strength exercises such as the Bulgarian squat, forward lunge and squat have been previously evaluated to study this hamstrings-quadriceps coactivation [7]; however, none have studied this coactivation pattern without the use of voluntary maximum isometric contraction. 
Such a study has not been carried out in soccer players either. Hence, this study aimed to compare: (i) the inter-limb differences in muscle activation; (ii) the intra-muscular group activation pattern and (iii) the activation pattern during different phases of the exercise. Based on previously published evidence, the following hypotheses were formulated: (1) Inter-limb differences would be noted for the different exercises. (2) Muscle activation would be different according to the phases of movement. (3) There would be a different pattern of intra-hamstrings and intra-quadriceps muscle group co-activation for each exercise.

\section{Materials and Methods}

\subsection{Ethical Considerations}

All participants gave their written informed consent to participate in the study. The study followed the guidelines of the Declaration of Helsinki and has been approved by the ethics committee of the Universidad Politécnica de Madrid.

\subsection{Participants}

Nineteen soccer players (age $=19.2 \pm 0.5$ years, height $=179.7 \pm 5.3 \mathrm{~cm}$, weight $=71.0 \pm 5.9 \mathrm{~kg}$ ) participated in the study, all of them men, belonging to the youth soccer team of a professional Spanish team. The players trained five days a week and played a match every week.

The inclusion criteria were to be contracted into the team at the time of data collection. The criteria for exclusion from the study were having a lower limb injury in the last six months or not having the consent of medical services at the time of the test.

\subsection{Study Design}

A descriptive study was carried out in a sports biomechanics laboratory, where participants were required to perform the Bulgarian squat, squat and lunge in a single session. All players performed the exercises in the same order:

1. Lunge. Prior to the start of the exercise, the position of reference (Figure 1) was determined, and the distance between the feet of each player was measured and marked on the ground with adhesive tape. To detect this position, the subject was placed in the reference position in such a way that the knee and hip of the forward leg and the delayed leg were at 90 degrees using the Lafayette Gollehon goniometer (Lafayette Instrument Company, Lafayette, IN, USA). The starting position was leg forward in contact with the ground and knee extended and back leg in contact with the ground and knee extended, with a straight trunk and looking forward. From the starting position, the subject had to bend the knees to lower the body, keeping the trunk straight. Once down, after two seconds the subject started the ascension phase extending both knees until the initial position with both feet in contact with the ground and knees extended. It was ensured that the knee of the advanced leg did not surpass the toe of the foot [7].

2. Bulgarian squat. The initial starting position (Figure 2) consisted of advancing one leg while the back leg was placed on an elevated surface of $50 \mathrm{~cm}$. The players then had to flex the forward knee while keeping the trunk straight [38].

3. Squat. The participant's feet were separated such that they were apart at shoulders' length (Figure 3), and the players had to lower themselves until they reached a $90^{\circ}$ knee flexion angle while the trunk was straight [39]. 


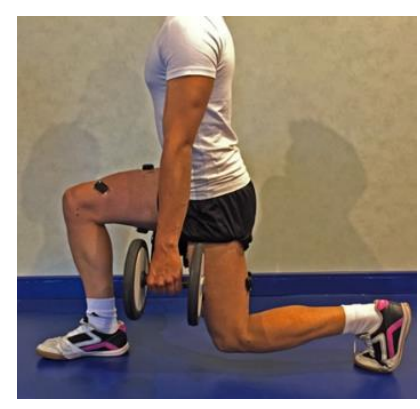

Figure 1. Lunge exercise.

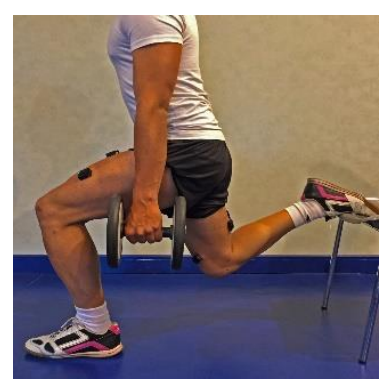

Figure 2. Bulgarian squat exercise.

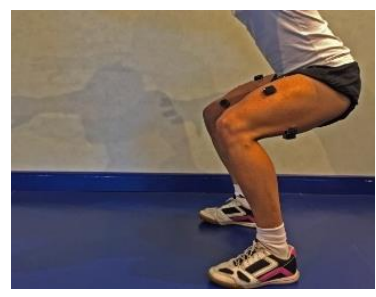

Figure 3. Squat exercise.

\subsection{Procedure}

The players first warmed up under the guidance of a strength and conditioning coach of the club. The warm-up consisted of seven minutes of running followed by joint mobility and core activation exercises for an additional three minutes. These strategies combine exercises of strength, flexibility and agility [40]. Finally, the players familiarized themselves with the three exercises at the end of the warm-up. The players during their normal training performed the three exercises as part of their physical preparation, so they were already used to the exercises. In addition, the players made eight repetitions without load, and the soccer players were guided at all times by the physical trainer of the club.

After warming up, sEMG sensors were placed on both thighs, on the rectus femoris (RF), vastus medialis (VM), vastus lateralis (VL), biceps femoris (BF) and semitendinosus (ST) with the players' skin being shaved and cleaned with alcohol prior to sensor placement. The sensors were always placed by the same person, the physical trainer. The Seniam protocol was used for sensor placement [41], and recommendations of Ramírez and Garzón [42] were followed, with the orientation for the rectus femoris being $0^{\circ}, 70^{\circ}$ for the vastus medialis and $-20^{\circ}$ for the vastus lateralis, taking as reference a line drawn from the origin and to the insertion.

sEMG data were recorded using Trigno ${ }^{\mathrm{TM}}$ Wireless System (Delsys, Inc., Boston, MA, USA). This system allowed players to perform the exercises with complete freedom of movement and was composed of a receiver device, a data registering software, and a series of surface wireless electrodes placed in each of the muscles, plus one placed on the back to be used as an accelerometer to discern the different phases of the exercises. The sensors measured $0.037 \times 0.026 \times 0.015 \mathrm{~m}$, with a distance 
between electrodes of $0.01 \mathrm{~m}$ and weighed $0.014 \mathrm{~kg}$ and could record both the sEMG signal and triaxial accelerometry. The input range was $0.011 \mathrm{~V}, 16$-bit resolution, bandwidth between $20-450 \mathrm{~Hz}$. Data were captured at $1500 \mathrm{~Hz}$. The signal gain of the electrodes was $909 \mathrm{~V} / \mathrm{V} \pm 5 \%$. The EMGWorks Acquisition software (Delsys, Inc., Massachusetts, MA, USA) was used to visualize and record the data.

Once the sensors were placed, the players performed the three exercises. Each player performed the same exercise twice, one dominant leg forward and one non-dominant leg forward. Each exercise had three well-differentiated phases, the first being the phase of descent, the second one being the isometric phase and finally the phase of ascent. Each exercise was repeated five times, and the execution rhythm was externally marked by a stopwatch: two seconds of descent, two seconds of isometric phase and two seconds of ascent. The external load used was 15\% of each player's weight. This external load was chosen because the players were used to performing the exercises with this load in training with the club. Between each exercise there was a complete rest of $2.5 \mathrm{~min}$.

\subsection{Data Processing}

The EMGWORKS ${ }^{\circledR}$ software (Version 4, Delsys, Inc., Boston, MA, USA) was used to process the data. The first step of the data treatment was the filtering of the signal using a 2nd order bandpass Butterworth filter [35] with an attenuation of $40 \mathrm{~dB}$ and a frequency cut between $20-300 \mathrm{~Hz}$ [43]. A root mean square (RMS) [44] with a window width of $0.05 \mathrm{~s}$ and a window overlap of $0.025 \mathrm{~s}$ was later applied to the filtered signal, and the signal offset was removed.

To identify the phases of the exercises, the accelerometer signal from a sensor placed on the back of the players in the longitudinal axis was used [45]. The sEMG and accelerometer signals were superimposed, and the mean RMS of the 5 repetitions was used for each of the 3 exercises for analysis.

\subsection{Statistical Analysis}

Four independent variables were defined: preferred limb, muscle group, phases of the exercise and exercise, and two dependent variables: intragroup muscular ratio and electrical activation (V) were compared. The intragroup muscular ratio expresses the activation of each muscle with respect to the total surface muscular activity of each muscle. To calculate the intragroup ratio, the signal of each muscle (RMS) was normalized by dividing it by the total signal of the muscle group. For example, the intragroup muscular activation for the $\mathrm{RF}=$ muscular activity (RMS) of RF/(muscular activities (RMS) of RF + VL + VM) ${ }^{*} 100$. The muscle activity used to make the ratio was the mean of the concentric, isometric and eccentric phases.

The statistical analyses were carried out with SPSS 23.0 (Armonk, NY: IBM Corp). To study the main effect, an analysis of variance was carried out of the 4 independent variables (leg (2) $\times$ muscle (5) $\times$ phases (3) $\times$ exercise (3)). Subsequent post-hoc comparisons were done with Bonferroni corrections. The significance level was set at 0.05 , and effect sizes were determined using eta squared.

\section{Results}

\subsection{Inter-Limb Effect}

Both the main effect of the leg factor $\left(\mathrm{F}_{1,13}=619 ; p=0.82 ; \eta^{2}=0.045\right)$ and the differences in intra-muscular group activation between dominant and non-dominant leg in each phase of the movement of each muscle in the exercises analyzed were not significant. Therefore, for the successive comparisons the mean activation between the two legs was used as the dependent variable.

\subsection{Intra-Muscular Group Activation Pattern}

Significant differences were found in the muscle activation between different muscles within the muscle group (quadriceps and hamstrings) for each of the exercises (Table 1): Bulgarian squat $\left(\mathrm{F}_{1,18}=331 ; p<0.001 ; \eta^{2}=0.80\right)$, lunge $\left(\mathrm{F}_{4,72}=114.5 ; p<0.001 ; \eta^{2}=0.86\right)$ and squat $\left(\mathrm{F}_{1,16}=247.31 ;\right.$ $\left.p<0.001 ; \eta^{2}=0.93\right)$. In the quadriceps, the post-hoc comparisons showed that the vastus medialis 
showed the highest activity, followed by the vastus lateralis and then the rectus femoris for all exercises $(p<0.001)$. In the hamstring muscles, the semitendinosus had greater activation than the biceps femoris $(p<0.001)$ for the Bulgarian squat and lunge exercises. However, in the squat no significant differences were obtained between the two muscles $(p=0.175)$. Comparisons between each muscle in the different exercises showed significant differences in the activation pattern $\left(\mathrm{F}_{8,128}=2 ; p=0.03\right.$; $\eta^{2}=0.93$ ) (Figure 4).

Table 1. Intra-muscular group activation (mean \pm standard deviation) in percentage.

\begin{tabular}{|c|c|c|c|c|c|c|c|c|c|}
\hline \multirow{3}{*}{$\begin{array}{c}\text { Muscle } \\
\text { RF } \\
\end{array}$} & \multicolumn{3}{|c|}{ Bulgarian Squat $(\mathrm{N}=19)$} & \multicolumn{3}{|c|}{ Lunge (N = 19) } & \multicolumn{3}{|c|}{ Squat $(N=19)$} \\
\hline & \multirow{2}{*}{$\begin{array}{c}\text { Mean } \pm \text { SD } \\
14.83 \pm 4.50 \% *\end{array}$} & \multicolumn{2}{|c|}{ CI $95 \%$} & \multirow{2}{*}{$\frac{\text { Mean } \pm \text { SD }}{16.56 \pm 5.70 \% *}$} & \multicolumn{2}{|c|}{ CI $95 \%$} & \multirow{2}{*}{$\begin{array}{c}\text { Mean } \pm \text { SD } \\
18.69 \pm 6.54 \% * \\
\end{array}$} & \multicolumn{2}{|c|}{ CI 95\% } \\
\hline & & 12.66 & 17.00 & & 13.81 & 19.31 & & 15.54 & 21.84 \\
\hline $\mathrm{VM}$ & $56.35 \pm 6.71 \%$ * & 53.12 & 59.58 & $58.85 \pm 8.02 \%$ * & 54.98 & 62.72 & $53.41 \pm 8.03 \%$ * & 49.54 & 57.28 \\
\hline VL & $29.17 \pm 5.19 \%$ * & 26.67 & 31.67 & $25.71 \pm 6.10 \%$ * & 22.77 & 28.65 & $28.67 \pm 6.90 \% *$ & 25.34 & 32.00 \\
\hline $\mathrm{BF}$ & $47.50 \pm 10 \%$ * & 42.68 & 52.32 & $44.35 \pm 6.93 \%$ * & 41.01 & 47.69 & $49.37 \pm 9.50 \%$ & 44.79 & 53.95 \\
\hline ST & $51.43 \pm 11.22 \%$ * & 46.02 & 56.84 & $55.65 \pm 6.94 \%$ * & 52.31 & 58.99 & $50.63 \pm 9.50 \%$ & 46.05 & 55.21 \\
\hline
\end{tabular}

\section{Activation Pattern}

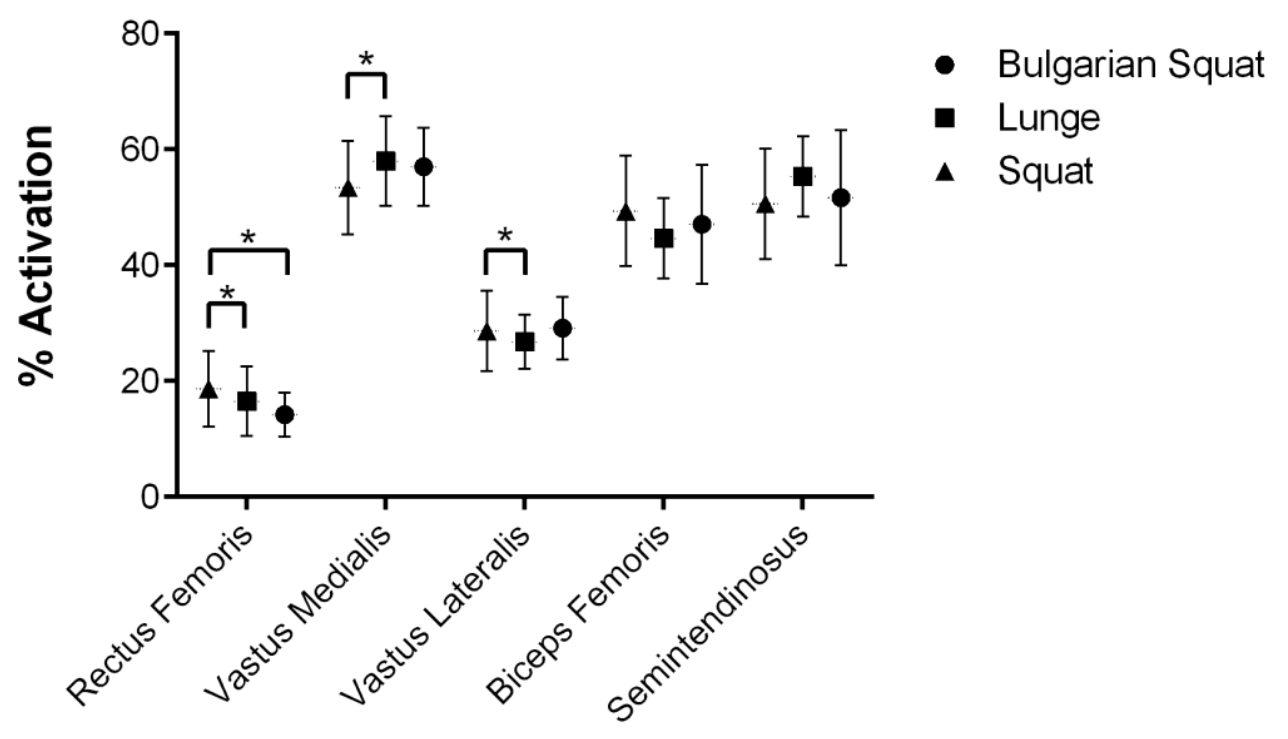

\section{Muscle}

Figure 4. Intra-muscular group activation pattern (mean \pm standard deviation) in percentage. The intragroup muscular ratio expresses the activation of each muscle with respect to the total surface muscular activity of each muscle. The brackets $\left({ }^{*}\right)$ with an asterisk show that there is a significant difference between these two exercises. The vertical lines around the data represent the standard deviation (SD).

\subsection{Electrical Activation During the Movement Phases}

Significant differences were found in the electrical activity (RMS) between the phases and in the three exercises $\left(\mathrm{F}_{2,26}=52.27 ; p=0.02 ; \eta^{2}=0.80\right)$.

In the Bulgarian squat exercise (Figure 5), significant differences were found between phases $\left(\mathrm{F}_{10,58}=12.18 ; p<0.001 ; \eta^{2}=0.68\right)$. In all quadriceps muscles, the isometric phase was the one that 
registered the greatest electrical activity $(p=0.01)$. The ascent phase had greater activation than the descent phase $(p=0.03)$. It was the vastus medialis muscle that showed the greatest activation of all in this phase. In the hamstrings, the ascent phase was greater than the other two $(p=0.02)$ in both biceps femoris and semitendinosus.

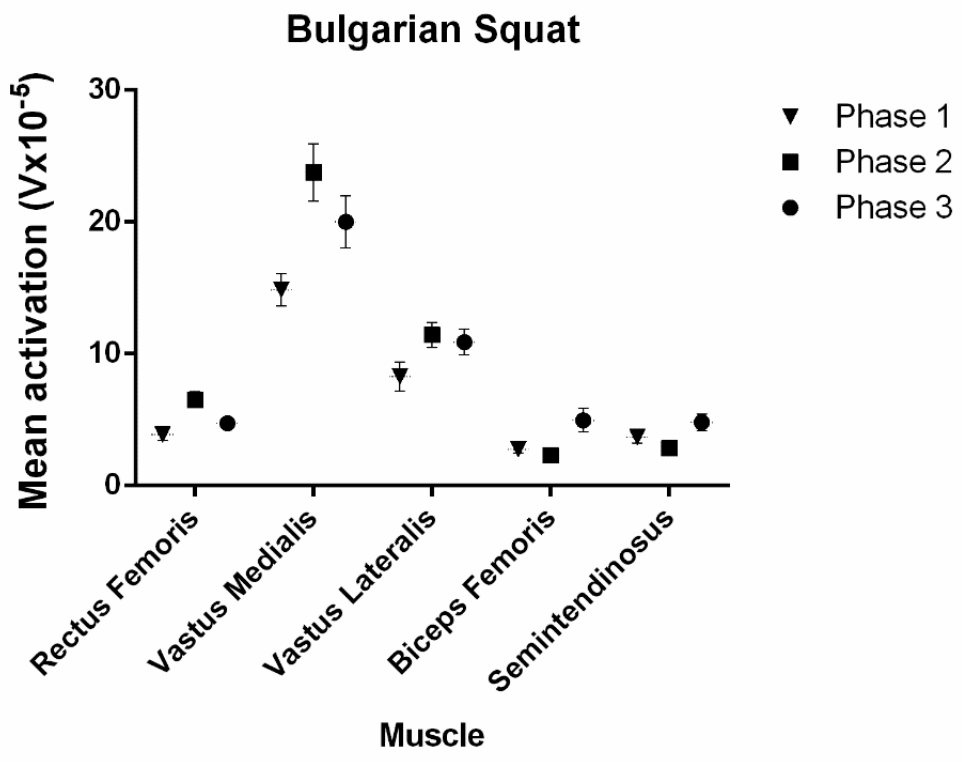

Figure 5. Mean activation $\left(\mathrm{V} \times 10^{-5}\right)$ of all the muscles in each phase in Bulgarian squat. The first phase corresponds to the descent, the second to the isometric phase and the third to the ascent. The vertical lines around the data represent the SD.

In the lunge exercise (Figure 6), significant differences were found between the three phases $\left(\mathrm{F}_{10,54}=16.85 ; p<0.001 ; \eta^{2}=0.76\right)$ for all muscle groups, except for the semitendinosus, where the descent and ascent phases had similar activation $(p=0.07)$.

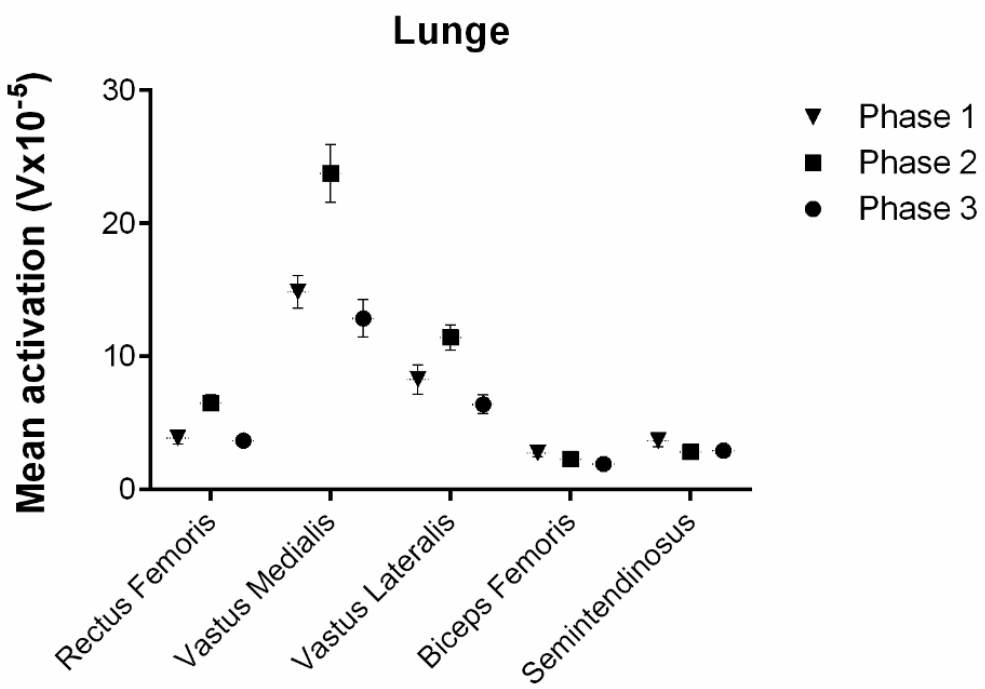

Muscle

Figure 6. Mean activation $\left(\mathrm{V} \times 10^{-5}\right)$ of all the muscles in each phase in lunge. The first phase corresponds to the descent, the second to the isometric phase and the third to the ascent. The vertical lines around the data represent the SD. 
In the squat exercise (Figure 7), there were significant differences between the phases $\left(F_{10,46}=8.04\right.$; $\left.p<0.001 ; \eta^{2}=0.64\right)$. In the rectus femoris, the isometric phase had greater activation than the descent and ascent phase $(p=0.04)$, and there were no significant differences between ascent phase and descent phase $(p=0.09)$. In the vastus medialis, the isometric phase had greater activation than the descent phase $(p<0.001)$, there were no significant differences between the isometric phase and the ascent phase $(p=0.25)$ and the ascent phase had greater activation than the descent phase $(p=0.04)$. In the vastus lateralis, the isometric phase had greater activation than the descent phase $(p=0.02)$, the ascent phase had greater activation than the descent phase $(p=0.03)$ and there was no difference between the isometric and ascent phase $(p=0.87)$. In biceps femoris and in the semitendinosus, the ascent phase had the highest activation $(p<0.001)$.

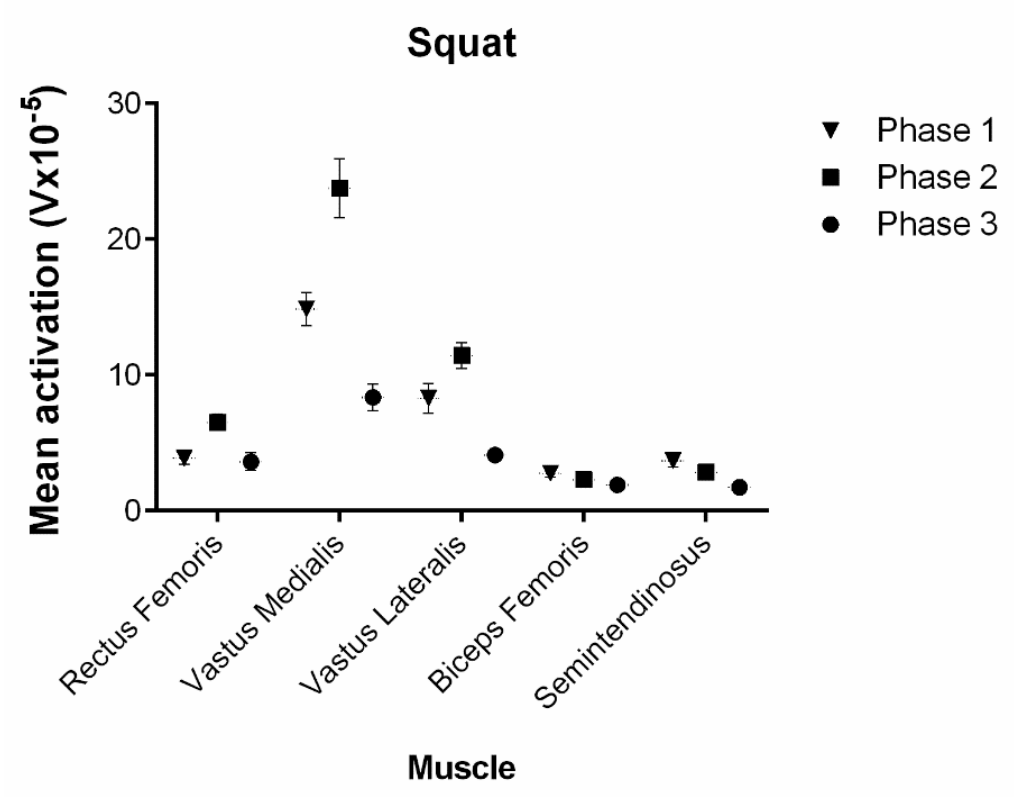

Figure 7. Mean activation $\left(\mathrm{V} \times 10^{-5}\right)$ of all the muscles in each phase in squat. The first phase corresponds to the descent, the second to the isometric phase and the third to the ascent. The vertical lines around the data represent the SD.

\section{Discussion}

In this study, the surface muscular activation of two important muscle groups, the hamstrings and the quadriceps, were measured in strength exercises in elite youth soccer players. These exercises are frequently used and easily replicable. No significant inter-limb differences were observed, rejecting hypothesis 1 . Muscle activation patterns showed differences across the intra-muscular group to which they belonged, confirming hypothesis 2 . Muscle activation differed across the concentric, isometric and eccentric phases of each exercise, confirming hypothesis 3 . This is one of the first investigations to study the muscle activation pattern in elite youth soccer players and has important applications where differences in the muscle activation pattern could indicate muscular deficiencies leading to other muscles assuming part of that deficiency.

The results show that no significant differences were found between dominant and non-dominant leg in electrical activity. Other previous studies obtained similar results with professional or semi-professional samples [46,47]. Although soccer is an asymmetric sport, the modern demands of the sport lay an emphasis on training both limbs equally. Another important factor to consider is that the participants in this study were elite youth players, playing in national and European competition. Previous research has shown inter-limb differences in strength decrease with an increase in level of play [48]. In fact, such inter-limb differences in strength could be a precursor to injuries [3], and hence the monitoring of inter limb differences could be important in injury prevention programs. 
In all exercises, the muscular activation patterns of the quadriceps muscles were repeated, with the vastus medialis being predominant, followed by the vastus lateralis and finally the rectus femoris (Figure 4). These results were similar to those obtained with amateur athletes previously for the lunge [18] and squat exercises [20,49]. The similar pattern of activation of quadriceps and hamstrings could indicate a synergy of work in the proposed exercises [50]. The results showed that there is a very similar activation pattern in the three exercises and in all the muscles (Figure 4). The activation pattern could be used after an injury as a way to quantify when the player has recovered his initial form, so it is important that sEMG tests are performed at different times of the season. This can be applied in the case of the patellofemoral pain syndrome, where vastus medialis activation is the primary goal in the early stages of recovery [51].

In the hamstrings, the greater intra-muscular activation (Figure 4) of the semitendinosus muscle compared to that of the biceps femoris account for its predominance [52,53]. A balance in the synergy of the hamstring muscles is important in the reduction of risk of a potential injury [53]. This synergy helps to reduce the tension on the biceps femoris [21,54], which plays a fundamental role in the hamstring injury, since biceps femoris is affected in $80 \%$ of all hamstring lesions [55]. A low hamstring to quadriceps ratio is believed to be a risk factor for injuries [56], and many rehabilitation and prevention programs focus on strengthening the hamstrings. The heterogeneity of activation pattern of different exercises must be taken into consideration when developing hamstring strength [29], and these exercises help in the coactivation of the hamstring and quadriceps muscle groups.

In the quadriceps, in all the muscles and exercises (Figures 5-7), greater activation was found in the ascent phase (concentric) than in the descent phase (eccentric), coinciding with previous studies [57,58]. In the concentric phase, there is a greater activation generated as there is a greater recruitment of fibers [59], while in the eccentric phase, a greater proportion of rapid contraction motor units were active at the expense of lesser recruitment of other motor units for load reduction [60]. This finding illustrates the contribution of the hamstrings to effective force production in the concentric phase of the squat. There are two major theories to justify less activation in the eccentric phase than in the concentric phase. It is believed that the lower amplitude of sEMG during eccentric phases may be due to the greater predominance of muscle-tendon strength produced by elongation in the eccentric phase [61]. Other authors, however, have proposed that differences in sEMG amplitude may be due to different neuronal pathways for each activation [60].

The isometric phase showed that rectus femoris presented the least activation in the quadriceps in all exercises, giving predominance in the stabilization of movement to the vastus medialis and vastus lateralis [59].

For the hamstrings muscles, there was greater activation in all phases in the Bulgarian squat (Figure 5) than in the normal squat (Figure 7), which may be due to a greater demand for co-activation of the posterior leg musculature to keep joints and the body stable [62]. Wright and Delong [53] emphasized the importance of the posterior muscles in exercises such as the Bulgarian squat, where the knee joint was fixed, thereby increasing the activation of the hamstrings.

These results can help sports scientists and strength and conditioning coaches, especially those working with youth players, when they want to influence a greater muscle activation for hypertrophy or implement these exercises in processes of strength development and rehabilitation.

The proposed exercises have been considered suitable for muscle evaluation and rehabilitation $[7,63]$ and have therefore been implemented in most soccer club training programs by physical trainers. The in-depth study of such exercises with a specific high-performance sample may allow soccer clubs to implement specific protocols for the development of lower train strength in players. An ineffective recovery of the thigh injury could cause a relapse in soccer [64], so it is vital to be able to correctly quantify the recovery process where sEMG can be used as a reliable method. Hence, the monitoring of such exercises could be used by sports scientists and strength and conditioning coaches. Nevertheless, the study had its limitations. The limitation of the study 
was mainly the size of the sample, which was restricted to uninjured players from one team due to the decision of the medical staff.

\section{Conclusions}

sEMG activation patterns in different muscles differed across the muscle group to which they belonged. Comparing the different phases of the exercises (the Bulgarian squat, the lunge and the squat), in the quadriceps the isometric phase had the greatest activation followed by the concentric and eccentric phases, while in the hamstrings the concentric phase was the one with the greatest activation.

Author Contributions: Conceptualization, G.T. and E.N.; methodology, G.T. and D.C.; software, A.N. and J.R.; validation, G.T., E.N. and L.F.; formal analysis, G.T. and A.N.; investigation, G.T. and D.C.; resources, L.F. and E.N.; data curation, G.T.; writing—original draft preparation, G.T.; writing—review and editing, G.T., E.N., J.R. and A.N.; visualization, G.T.; supervision, E.N.; project administration, E.N. All authors have read and agreed to the published version of the manuscript.

Funding: This research received no external funding.

Conflicts of Interest: The authors declare no conflict of interest.

\section{References}

1. Philippaerts, R.M.; Vaeyens, R.; Janssens, M.; Van Renterghem, B.; Matthys, D.; Craen, R.; Bourgois, J.; Vrijens, J.; Beunen, G.; Malina, R. The relationship between peak height velocity and physical performance in youth soccer players. J. Sports Sci. 2006, 24, 221-230. [CrossRef] [PubMed]

2. Di Salvo, V.; Baron, R.; Tschan, H.; Montero, F.C.; Bachl, N.; Pigozzi, F. Performance characteristics according to playing position in elite soccer. Int. J. Sports Med. 2007, 28, 222-227. [CrossRef] [PubMed]

3. Daneshjoo, A.; Rahnama, N.; Mokhtar, A.H.; Yusof, A. Effectiveness of injury prevention programs on developing quadriceps and hamstrings strength of young male professional soccer players. J. Hum. Kinet. 2013, 39, 115-125. [CrossRef] [PubMed]

4. Evangelidis, P.E.; Pain, M.T.; Folland, J. Angle-specific hamstring-to-quadriceps ratio: A comparison of football players and recreationally active males. J. Sports Sci. 2015, 33, 309-319. [CrossRef]

5. Houweling, T.A.; Head, A.; Hamzeh, M.A. Validity of isokinetic testing for previous hamstring injury detection in soccer players. Isokinet. Exerc. Sci. 2009, 17, 213-220. [CrossRef]

6. Kannus, P. Isokinetic evaluation of muscular performance. Int. J. Sports Med. 1994, 15, S11-S18. [CrossRef]

7. Begalle, R.L.; DiStefano, L.J.; Blackburn, T.; Padua, D.A. Quadriceps and Hamstrings Coactivation during Common Therapeutic Exercises. J. Athl. Train. 2012, 47, 396-405. [CrossRef]

8. Dedinsky, R.; Baker, L.; Imbus, S.; Bowman, M.; Murray, L. Exercises that facilitate optimal hamstring and quadriceps co-activation to help decrease acl injury risk in healthy females: A systematic review of the literature. Int. J. Sports Phys. Ther. 2017, 12, 3.

9. Ebben, W. Hamstring activation during lower body resistance training exercises. Int. J. Sports Physiol. Perform. 2009, 4, 84-96. [CrossRef]

10. Duhig, S.J.; Williams, M.D.; Minett, G.M.; Opar, D.; Shield, A.J. Drop punt kicking induces eccentric knee flexor weakness associated with reductions in hamstring electromyographic activity. J. Sci. Med. Sport 2017, 20, 595-599. [CrossRef]

11. Rouissi, M.; Chtara, M.; Owen, A.; Chaalali, A.; Chaouachi, A.; Gabbett, T.; Chamari, K. Effect of leg dominance on change of direction ability amongst young elite soccer players. J. Sports Sci. 2016, 34, 542-548. [CrossRef] [PubMed]

12. Cortis, C.; Tessitore, A.; Perroni, F.; Lupo, C.; Pesce, C.; Ammendolia, A.; Capranica, L. Interlimb coordination, strength, and power in soccer players across the lifespan. J. Strength Cond. Res. 2009, 23, 2458-2466. [CrossRef] [PubMed]

13. Navandar, A.; Veiga, S.; Torres, G.; Chorro, D.; Navarro, E. A previous hamstring injury affects kicking mechanics in soccer players. J. Sports Med. Phys. Fit. 2018, 58, 1815-1822. [CrossRef] [PubMed]

14. Daneshjoo, A.; Rahnama, N.; Mokhtar, A.H.; Yusof, A. Bilateral and unilateral asymmetries of isokinetic strength and flexibility in male young professional soccer players. J. Hum. Kinet. 2013, 36, 45-53. [CrossRef] [PubMed] 
15. Montini, M.; Felici, F.; Nicolo, A.; Sacchetti, M.; Bazzucchi, L. Neuromuscular demand in a soccer match assessed by a continuous electromyographic recording. J. Sports Med. Phys. Fit. 2017, 57, 345-352.

16. LaPrade, R.F.; Surowiec, R.K.; Sochanska, A.N.; Hentkowski, B.S.; Martin, B.M.; Engebretsen, L.; Wijdicks, C.A. Epidemiology, identification, treatment and return to play of musculoskeletal-based ice hockey injuries. $\mathrm{Br}$. J. Sports Med. 2014, 48, 4-10. [CrossRef]

17. Farrokhi, S.; Pollard, C.D.; Souza, R.B.; Chen, Y.-J.; Reischl, S.; Powers, C.M. Trunk position influences the kinematics, kinetics, and muscle activity of the lead lower extremity during the forward lunge exercise. J. Orthop. Sports Phys. Ther. 2008, 38, 403-409. [CrossRef]

18. Pincivero, D.M.; Aldworth, C.; Dickerson, T.; Petry, C.; Shultz, T. Quadriceps-hamstring EMG activity during functional, closed kinetic chain exercise to fatigue. Eur. J. Appl. Physiol. 2000, 81, 504-509. [CrossRef]

19. Boudreau, S.N.; Dwyer, M.K.; Mattachola, C.G.; Lattermann, C.; Uhl, T.L.; McKeon, J.M. Hip-muscle activation during the lunge, single-leg squat, and step-up-and-over exercises. J. Sport Rehabil. 2009, 18, 91-103. [CrossRef]

20. Caterisano, A.; Moss, R.E.; Pellinger, T.K.; Woodruff, K.; Lewis, V.C.; Booth, W.; Khadra, T. The effect of back squat depth on the EMG activity of 4 superficial hip and thigh muscles. J. Strength Cond. Res. 2002, 16, 428-432.

21. McCurdy, K.; O’Kelley, E.; Kutz, M.; Langford, G.; Ernest, J.; Torres, M. Comparison of lower extremity EMG between the 2-leg squat and modified single-leg squat in female athletes. J. Sport Rehabil. 2010, 19, 57-70. [CrossRef] [PubMed]

22. Ekstrand, J.; Hägglund, M.; Waldén, M. Injury incidence and injury patterns in professional football: The UEFA injury study. Br. J. Sports Med. 2011, 45, 553-558. [CrossRef] [PubMed]

23. Ekstrand, J.; Waldén, M.; Hägglund, M. Hamstring injuries have increased by $4 \%$ annually in men's professional football, since 2001: A 13-year longitudinal analysis of the UEFA Elite Club injury study. Br. J. Sports Med. 2016, 50, 731-737. [CrossRef] [PubMed]

24. Croisier, J.-L. Factors associated with recurrent hamstring injuries. Sports Med. 2004, 34, 681-695. [CrossRef]

25. Fousekis, K.; Tsepis, E.; Poulmedis, P.; Athanasopoulos, S.; Vagenas, G. Intrinsic risk factors of non-contact quadriceps and hamstring strains in soccer: A prospective study of 100 professional players. Br. J. Sports Med. 2011, 45, 709-714. [CrossRef]

26. Aagaard, P.; Simonsen, E.B.; Andersen, J.L.; Magnusson, S.P.; Bojsen-Moller, F.; Dyhre-Poulse, P. Antagonist muscle coactivation during isokinetic knee extension. Scand. J. Med. Sci. Sports 2000, 10, 58. [CrossRef]

27. Beyer, K.S.; Fukuda, D.; Miramonti, A.M.; Church, D.; Tanigawa, S.; Stout, J.R.; Hoffman, J.R. Strength ratios are affected by years of experience in American collegiate rugby athletes: A preliminary study. Isokinet. Exerc. Sci. 2016, 24, 257-262. [CrossRef]

28. Van der Horst, N.; Smits, D.; Petersen, J.; Goedhart, E.A.; Backx, F. The preventive effect of the Nordic hamstring exercise on hamstring injuries in amateur soccer players: A randomized controlled trial. Am. J. Sports Med. 2015, 43, 1316-1323. [CrossRef]

29. Bourne, M.N.; Williams, M.D.; Opar, D.; Al Najjar, A.; Kerr, G.K.; Shield, A.J. Impact of exercise selection on hamstring muscle activation. Br. J. Sports Med. 2017, 51, 1021-1028. [CrossRef]

30. Guex, K.; Millet, G.P. Conceptual framework for strengthening exercises to prevent hamstring strains. Sports Med. 2013, 43, 1207-1215. [CrossRef]

31. Brukner, P. Hamstring injuries: Prevention and treatment-An update. Br. J. Sports Med. 2015, 49, 1241-1244. [CrossRef] [PubMed]

32. Heckmann, T.P.; Noyes, F.R.; Barber-Westin, S. Rehabilitation after ACL reconstruction. In ACL Injuries in the Female Athlete; Springer: Berlin/Heidelberg, Germany, 2018; pp. 505-535.

33. Irish, S.E.; Millward, A.J.; Wride, J.; Haas, B.M.; Shum, G.L. The effect of closed-kinetic chain exercises and open-kinetic chain exercise on the muscle activity of vastus medialis oblique and vastus lateralis. J. Strength Cond. Res. 2010, 24, 1256-1262. [CrossRef] [PubMed]

34. Charlton, P.C.; Drew, M.K.; Mentiplay, B.F.; Grimaldi, A.; Clark, R.A. Exercise interventions for the prevention and treatment of groin pain and injury in athletes: A critical and systematic review. Sports Med. 2017, 47, 2011-2026. [CrossRef] [PubMed]

35. Robertson, D.; Dowling, J. Design and responses of Butterworth and critically damped digital filters. J. Electromyogr. Kinesiol. 2003, 13, 569-573. [CrossRef] 
36. Marras, W.S.; Davis, K.G. A non-MVC EMG normalization technique for the trunk musculature: Part 1. Method development. J. Electromyogr. Kinesiol. 2001, 11, 1-9. [CrossRef]

37. Suydam, S.M.; Manal, K.; Buchanan, T.S. The advantages of normalizing electromyography to ballistic rather than isometric or isokinetic tasks. J. Appl. Biomech. 2017, 33, 189-196. [CrossRef]

38. Andersen, V.; Fimland, M.S.; Brennset, O.; Haslestad, L.R.; Lundteigen, M.S.; Skalleberg, K.; Saeterbakken, A.H. Muscle activation and strength in squat and bulgarian squat on stable and unstable surface. Int. J. Sports Med. 2014, 35, 1196-1202. [CrossRef]

39. Chiu, L.Z.; Burkhardt, E. A teaching progression for squatting exercises. Strength Cond. J. 2011, 33, 46-54. [CrossRef]

40. Herman, K.; Barton, C.; Malliaras, P.; Morrissey, D. The effectiveness of neuromuscular warm-up strategies, that require no additional equipment, for preventing lower limb injuries during sports participation: A systematic review. BMC Med. 2012, 10, 75. [CrossRef]

41. Hermens, H.J.; Freriks, B.; Disselhorst-Klug, C.; Rau, G. Development of recommendations for SEMG sensors and sensor placement procedures. J. Electromyogr. Kinesiol. 2000, 10, 361-374. [CrossRef]

42. Ramírez, A.; Garzón, D.A. Análisis de sensibilidad por la colocación de los electrodos en la electromiografía de superficie (semg). Rev. Fac. Ing. 2013, 46, 70-79.

43. De Luca, C.; Gilmore, L.D.; Kuznetsov, M.; Roy, S.H. Filtering the surface EMG signal: Movement artifact and baseline noise contamination. J. Biomech. 2010, 43, 1573-1579. [CrossRef] [PubMed]

44. Fukuda, T.Y.; Echeimberg, J.O.; Pompeu, J.E.; Lucareli, P.; Garbelotti, S.; Gimenes, R.O.; Ampolinario, A. Root mean square value of the electromyographic signal in the isometric torque of the quadriceps, hamstrings and brachial biceps muscles in female subjects. J. Appl. Res. 2010, 10, 32-39.

45. Yoo, W. Comparison of hamstring-to-quadriceps ratio between accelerating and decelerating sections during squat exercise. J. Phys. Ther. Sci. 2016, 28, 2468-2469. [CrossRef] [PubMed]

46. Hoshikawa, Y.; Lida, T.; Murumatssu, M.; Nakajima, Y.; Fukunaga, T.; Kanehisa, H. Differences in thigh muscularity and dynamic torque between junior and senior soccer players. J. Sports Sci. 2009, 27, 129-138. [CrossRef] [PubMed]

47. Zakas, A. Bilateral isokinetic peak torque of quadriceps and hamstring muscles in professional soccer players with dominance on one or both two sides. J. Sports Med. Phys. Fit. 2006, 46, 28.

48. Fousekis, K.; Tsepis, E.; Vagenas, G. Lower limb strength in professional soccer players: Profile, asymmetry, and training age. J. Sports Sci. Med. 2010, 9, 364-373.

49. Schwanbeck, S.; Chilibeck, P.D.; Binsted, G. A comparison of free weight squat to Smith machine squat using electromyography. J. Strength Cond. Res. 2009, 23, 2588-2591. [CrossRef]

50. Housh, T.J.; deVries, H.A.; Johnson, G.O.; Housh, D.J.; Evans, S.A.; Stout, J.R.; Evetovich, T.K.; Bradway, R.M. Electromyographic fatigue thresholds of the superficial muscles of the quadriceps femoris. Eur. J. Appl. Physiol. Occup. Physiol. 1995, 71, 131-136. [CrossRef]

51. Crossley, K.; Bennell, K.; Green, S.; MaConnell, J. A systematic review of physical interventions for patellofemoral pain syndrome. Clinical J. Sport Med. 2001, 11, 103-110. [CrossRef]

52. Ninos, J.C.; Irrgang, J.J.; Burdett, R.; Weiss, J.R. Electromyographic analysis of the squat performed in self-selected lower extremity neutral rotation and 30 of lower extremity turn-out from the self-selected neutral position. J. Orthop. Sports Phys. Ther. 1997, 25, 307-315. [CrossRef] [PubMed]

53. Wright, G.; Delong, T.; Gehlsen, G. Electromyographic Activity of the Hamstrings during Performance of the Leg Curl, Stiff-Leg Deadlift, and Back Squat Movements. J. Strength Cond. Res. 1999, 13, 168-174.

54. Schuermans, J.; Van Tiggelen, D.; Danneels, L.; Witvrouw, E. Biceps femoris and semitendinosus-teammates or competitors? New insights into hamstring injury mechanisms in male football players: A muscle functional MRI study. B. J. Sports Med. 2014, 48, 1599-1606. [CrossRef] [PubMed]

55. Thelen, D.G.; Chumanov, E.S.; Sherry, M.A.; Heiderscheit, B.C. Neuromusculoskeletal models provide insights into the mechanisms and rehabilitation of hamstring strains. Exerc. Sport Sci. Rev. 2006, 34, 135-141. [CrossRef] [PubMed]

56. Coombs, R.; Garbutt, G. Developments in the use of the hamstring/quadriceps ratio for the assessment of muscle balance. J. Sports Sci. Med. 2002, 1, 56-62.

57. Ebben, W.E.; Jensen, R.L. Electromyographic and kinetic analysis of traditional, chain, and elastic band squats. J. Strength Cond. Res. 2002, 16, 547-550. 
58. Yavuz, H.U.; Erdag, D.; Amca, A.M.; Aritan, S. Kinematic and EMG activities during front and back squat variations in maximum loads. J. Sports Sci. 2015, 33, 1058-1066. [CrossRef]

59. Pincivero, D.M.; Gandhi, V.; Timmons, M.K.; Coelho, A.J. Quadriceps femoris electromyogram during concentric, isometric and eccentric phases of fatiguing dynamic knee extensions. J. Biomech. 2006, 39, $246-254$. [CrossRef]

60. Nardone, A.; Romano, C.; Schieppati, M. Selective recruitment of high-threshold human motor units during voluntary isotonic lengthening of active muscles. J. Physiol. 1989, 409, 451-471. [CrossRef]

61. Laidlaw, D.H.; Bilodeau, M.; Enoka, R.M. Steadiness is reduced and motor unit discharge is more variable in old adults. Muscle Nerve Off. J. Am. Assoc. Electrodiagn. Med. 2000, 23, 600-612. [CrossRef]

62. Behm, D.G.; Anderson, K.; Curnew, R.S. Muscle force and activation under stable and unstable conditions. J. Strength Cond. Res. 2002, 16, 416-422. [PubMed]

63. Jönhagen, S.; Halvorsen, K.; Benoit, D.L. Muscle activation and length changes during two lunge exercises: Implications for rehabilitation. Scand. J. Med. Sci. Sports 2009, 19, 561-568. [CrossRef] [PubMed]

64. Heiderscheit, B.C.; Sherry, M.A.; Silder, A.; Chumanov, E.S.; Thelen, D.G. Hamstring strain injuries: Recommendations for diagnosis, rehabilitation, and injury prevention. J. Orthop. Sports Phys. Ther. 2010, 40, 67-81. [CrossRef] [PubMed]

(C) 2020 by the authors. Licensee MDPI, Basel, Switzerland. This article is an open access article distributed under the terms and conditions of the Creative Commons Attribution (CC BY) license (http://creativecommons.org/licenses/by/4.0/). 